\title{
Optic nerve compression due to allergic fungal rhinosinusitis
}

\author{
Anupam Kanodia, Nisha Tandan, Rajeev Kumar, Prem Sagar (1)
}

Otorhinolaryngology-Head \& Neck Surgery, All India Institute of Medical Sciences, New Delhi, Delhi, India

\section{Correspondence to Dr Rajeev Kumar; rajeev9843@yahoo.co.in}

Accepted 24 September 2020

\section{DESCRIPTION}

A 3-week postpartum 25-year-old woman presented to ophthalmology emergency department during the COVID-19 pandemic with complete blindness in the right eye for the last 4 months and gradually progressive vision loss in the left eye with nasal stuffiness for the last 20 days. She reported no blood-stained nasal discharge, headache or symptoms pertaining to allergic rhinitis. Physical examination revealed loss of light perception in the right eye and perception of hand movements close to face in the left eye. Abaxial proptosis was present in the left eye (figure 1). Extraocular movements were not restricted in either eye. An MRI to evaluate the optic nerve revealed an isointense lesion on T1-weighted images and a signal void on T2-weighted images involving bilateral ethmoid sinuses, bilateral sphenoid sinuses and both orbits, with significant sinus expansion (figure 2A,B). The patient was diagnosed to have allergic fungal rhinosinusitis (AFRS), and she underwent endoscopic sinus surgery. This

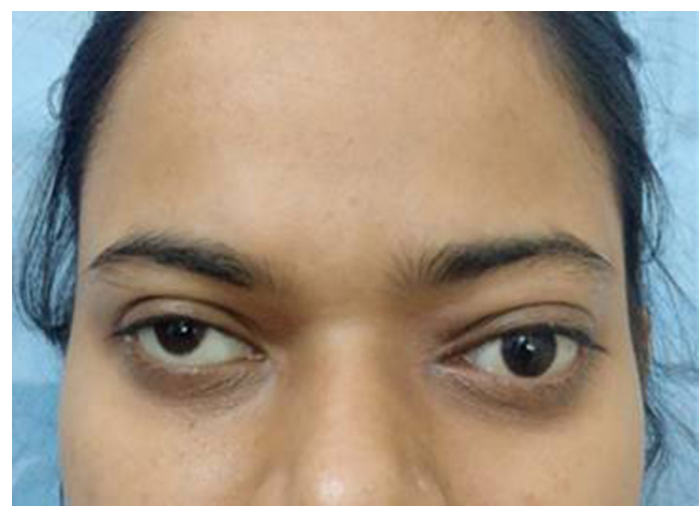

Figure 1 Clinical picture showing left-sided abaxial proptosis.

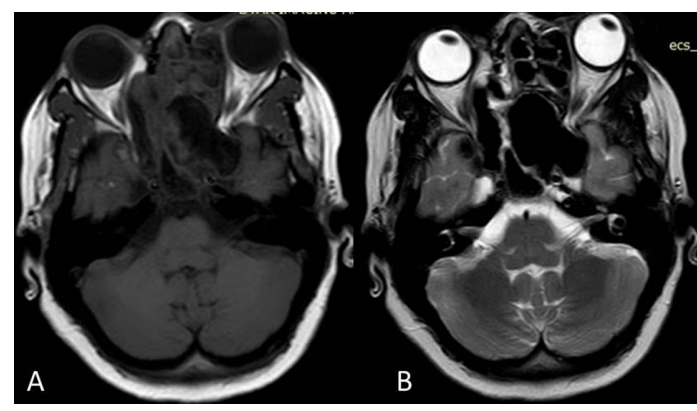

Figure 2 T2-weighted MRI showing ethmoidal sinus expansion with signal void (A); T1-weighted MRI showing hypointense to isointense soft tissue density filling up the bilateral ethmoid and sphenoid sinuses (B) patient's left eye vision improved to 6/12 within 2 days of surgery, whereas her right eye did not show any improvement.

AFRS occurs due to chronic non-invasive fungal infection in an immunocompetent atopic individual, usually from an area with warm and humid climate. Both type I and III hypersensitivity contribute to its pathogenesis. ${ }^{1}$ AFRS presents with symptoms of chronic rhinosinusitis such as nasal obstruction, nasal discharge, postnasal drip, hyposmia, facial pressure and pain. It is not uncommon for a patient to present with ophthalmic manifestations of AFRS such as diplopia, proptosis and vision loss, which have been reported in up to $57 \%$ of the patients. ${ }^{2}$ The mechanism behind visual impairment is thought to be pressure-induced ischaemia of the optic nerve, which occurs due to the bone-eroding tendency of the disease. In this case, dehiscence of the left optic nerve can be seen in the sphenoid sinus (figure 3), allowing compression by the disease.

On CT imaging, one appreciates pansinusitis with heterogeneous densities, usually hyperdense areas surrounded by hypodense soft tissue as in figure 4 in this case. It shows how lamina papyracea is being pushed laterally on the left side,

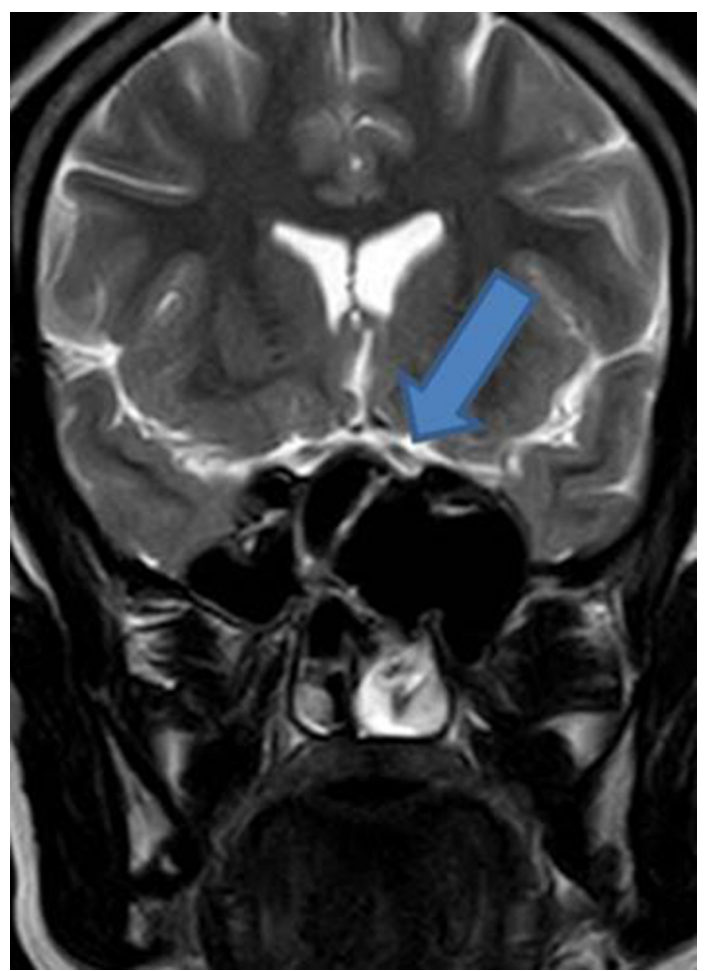

Figure 3 Coronal T2-weighted MRI showing bilaterally dehiscent optic nerve (arrow). 


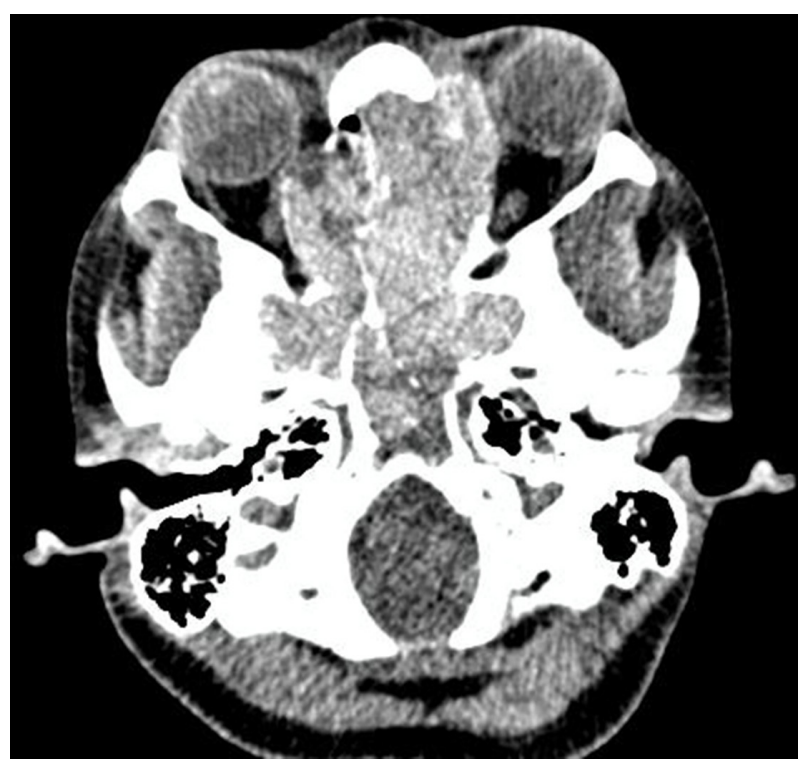

Figure 4 Axial CT soft tissue window demonstrating that the disease involving the left anterior and posterior ethmoids has pushed the lamina papyracea anterolaterally causing proptosis.

leading to abaxial proptosis. MRI reveals heterogeneous intensities on T1-weighted images and characteristic signal voids on T2-weighted images. ${ }^{3}$ The inflamed mucosa is usually hyperintense on T2 and enhances on administration of gadolinium contrast. Although CT is recommended as the radiology of choice, MRI is ordered to evaluate the intracranial extension of disease or the optic nerve, as in this case.

Visual loss should be treated on urgent basis, and surgery forms the mainstay of treatment. Endoscopic sinus surgery, by removing the fungal debris and polyps, decompresses the sphenoid sinuses and hence restores the vascular supply to the optic nerve. In this case, the fundus examination revealed pale optic disc on the right side and mild temporal disc pallor on the left side; left optic disc pallor resolved 48 hours after the procedure, implying a restored blood supply. The right disc remained completely pale. Systemic corticosteroids may be used in the perioperative period to improve vascular supply to the optic nerve. ${ }^{4}$ Postoperatively, topical corticosteroids and alkaline nasal douching are recommended to hasten cavity healing and reduce recurrence rates. There is insufficient evidence to recommend the use of topical or systemic antifungals. ${ }^{5}$

Proptosis and vision impairment usually reverse once the ethmoidal labyrinth and sphenoid sinus are decompressed.

\section{Patient's perspective}

I was ignorant about the visual complaints initially and attributed it to pregnancy. However, it kept on progressing even in the postpartum period due to which I consulted the eye specialist. Further evaluation showed a surgically correctable lesion, and I was referred to otorhinolaryngology specialists. I underwent surgery and can see much better from my left eye. I have been told that my right eye vision might not improve at all. I wish I had not ignored my complaints despite the pregnancy and COVID-19 pandemic.

\section{Learning points}

- Vision complaints should not be taken lightly, as a delay may lead to irreversible vision loss.

- Endoscopic sinus surgery, by decompressing the paranasal sinuses, restores the optic nerve's blood supply and may reverse recent-onset visual deterioration due to allergic fungal rhinosinusitis.

However, long-standing vision loss (>6 months) and complete vision loss carry a poor prognosis for visual recovery. ${ }^{2}$

Contributors AK and NT were involved in clinical care of the patient and data collection. AK wrote the first draft which was critically reviewed by PS. RK supervised the clinical care and the final draft of the manuscript.

Funding The authors have not declared a specific grant for this research from any funding agency in the public, commercial or not-for-profit sectors.

Competing interests None declared.

Patient consent for publication Obtained.

Provenance and peer review Not commissioned; externally peer reviewed.

ORCID iD

Prem Sagar http://orcid.org/0000-0001-5590-9279

\section{REFERENCES}

1 Callejas CA, Douglas RG. Fungal rhinosinusitis: what every allergist should know. Clin Exp Allergy 2013;43:835-49.

2 Thakar A, Lal P, Dhiwakar M, et al. Optic nerve compression in allergic fungal sinusitis. J Laryngol Otol 2011;125:381-5.

3 Gavito-Higuera J, Mullins CB, Ramos-Duran L, et al. Sinonasal fungal infections and complications: a pictorial review. J Clin Imaging Sci 2016;6:23.

4 Vashishth $\mathrm{A}$. Extensive allergic fungal rhinosinusitis: ophthalmic and skull base complications. Indian J Otolaryngol Head Neck Surg 2015;67:227-33.

5 Head K, Sharp S, Chong L-Y, et al. Topical and systemic antifungal therapy for chronic rhinosinusitis. Cochrane Database Syst Rev 2018;16.

Copyright 2020 BMJ Publishing Group. All rights reserved. For permission to reuse any of this content visit

https://www.bmj.com/company/products-services/rights-and-licensing/permissions/

BMJ Case Report Fellows may re-use this article for personal use and teaching without any further permission.

Become a Fellow of BMJ Case Reports today and you can:

- Submit as many cases as you like

- Enjoy fast sympathetic peer review and rapid publication of accepted articles

- Access all the published articles

Re-use any of the published material for personal use and teaching without further permission

Customer Service

If you have any further queries about your subscription, please contact our customer services team on +44 (0) 2071111105 or via email at support@bmj.com.

Visit casereports.bmj.com for more articles like this and to become a Fellow 